\title{
Energy savings potential from prismatic glass structure
}

\author{
Viacheslav Shemelin, Tomas Matuska, Borivoj Sourek and Vladimir Jirka \\ University Centre for Energy Efficient Buildings, Czech Technical University in Prague, Trinecka 1024, 27343 Bustehrad, Czech \\ Republic
}

\begin{abstract}
The simulation analysis of the potential energy savings from the prismatic glass structure has been provided. The two conventional triple glazings and two proposed triple glazings with prismatic glass have been experimentally tested to obtain the realistic angular selective optical properties. The experimental results have been compared with conventional triple glazing with clear glass panes and triple glazing with solar control pane applied. The comparison indicated high potential advantages of triple glazing with prismatic glass structures (especially for reverse symmetrical prism): low transmittance for high solar altitude-summer condition, high transmittance for low solar altitude-winter condition. The obtained transmittance characteristics were used as input data for the annual simulation of a typical office in the Czech Republic. The simulation has been performed in TRNSYS and TRNBuild software. The gathered results confirmed, that prismatic glass structure can bring energy savings for both cooling and heating energy demands.
\end{abstract}

\section{Introduction}

Nowadays buildings operation accounts for more than $40 \%$ of the total energy use in Europe. Therefore, it is obvious that the building sector needs particular attention in order to reach a sustainable development. The European Union adopted the Energy Performance of Buildings Directive (EPBD) in 2002 with the aim to increase the energy efficiency of buildings. High-level requirements, as a result of the EPBD, put a significant pressure to design and construct energy efficient buildings. On the other hand, it is highly important to keep in mind, that the main building purpose is to provide housing for occupants, shelter them from uncomfortable outdoor climatic conditions and provide them comfortable and healthy indoor environment. In this regard, to achieve zero energy buildings (ZEB) or the nearly-zero energy buildings (NZEB) goal, solar heat gains should be managed effectively while visual discomfort and glare are minimized [1-3].

Solar radiation influences the energy consumption in different ways in different seasons. In summer, excessive solar heat gains result in higher energy consumption due to the increased cooling load requirement; in winter, solar radiation entering through the openings in the facade can provide passive solar heating; in all seasons of the year the solar radiation improves the daylight quality. Welldesigned solar control devices can significantly reduce the energy demand of the buildings and enhance the natural daylight utilization in the indoor environment.

Many different principles to control the solar heat gains exist. The majority of solar control systems must respect window orientation, room configuration, and latitude [4-6]. Static devices such as overhangs and louvres affect the architectural and structural design of a building and must be considered at the start of the design phase as they require a defined geometry significantly associated with the building architectural design. Sunblinds, shutters, and other external dynamic shading devices can be used to block the solar radiation before it reaches the interior environment [7]. Manual control by occupants could result finally in thermal and visual discomfort [8]. The solution is application of automated blinds [9]. On the other side, they are relatively complex and expensive because of their moveable parts. Moreover, automated external shading devices can negatively affect natural daylighting and finally increase the electric demand for lighting if not equipped with complex predictive control and sensors $[10,11]$.

An alternative approach to control the solar heat gains is the use of special prismatic structures. Prismatic panes are structured transparent devices made of clear glass or acrylic material that are used to redirect or refract sun rays. The possibility of controlling the direct solar radiation with prismatic systems has been described by many authors in the past. Senzo [12] presented a light transmitting panel which consists of pair of transparent plates each provided with a plurality of adjacent prisms and capable of redirecting the solar radiation incident in a predetermined range. Koster [13] investigated a glazing unit which uses horizontal, specular profile bars in the intermediate space between the two panes of a glazing system and to transmit it into the room during winter and to reject the direct solar radiation during summer. Yonah [14] described a one layer panel, comprising a plurality of adjacent triangular prisms, which transmits sun rays incident at a specific range of incidence angles while reflecting sun rays incident out of given range. Critten 
[15] later concluded that prismatic glass could be used to enhance winter sunlight in greenhouses, further Kurata [16] demonstrated the effects of a Fresnel prism in a greenhouse cover, concluding that the transmission of light in winter was increased while in summer it decreased. A new design of prismatic pane with two refracting surfaces had been investigated by Christoffers [17]. Later Lorenz [18,19] presented the advantages of prismatic glazing unit in comparison to double glazing unit and solar control glazing unit. The use of passive prismatic glazing for reduction of the greenhouse energy consumption has been investigated by Korecko et al. [20]. Sabry [21] studied the use of asymmetric prism combined with low concentration PV in the façades. Walze et al. [22] analysed microstructured prismatic structures combined with different kinds of functional coatings. Shehabi et al. researched a potential of the dynamic prismatic window coating that can continuously control incoming light to maximize the performance and energy savings.

Another approach how to control solar heat gains is use of static angular selective films and coatings, which transmit the daylight within a specific range of incident solar altitude angles. Mbise et al. [23] provided an experiment, comparing experimentally the efficiency of singular-selective metal-containing films. Further Zakirullin and Letuta [24] presented a new optical filter with the angular selective light transmission for application in single or double glazed smart window.

In the present study, the experimental characterization of two different glazings with prismatic structures have been presented. Subsequently, the experimental characterization results have been used for annual simulation of a typical office building in the Czech Republic. Finally, the simulation results have been compared with conventional clear triple glazing and solar control triple glazing which are still the only wide spread competitive solution in the building practice today.

\section{Glazing structures}

Four different glazing configurations have been experimentally tested to characterize the angle dependent solar radiation transmittance. Standard clear triple glazing (A) and conventional solar protection glazing (B) were tested as the reference glazing for comparison purposes. Each tested sample contains one glass pane with a low emissivity coating to provide the identical thermal properties. The investigated alternatives $\mathrm{C}$ and $\mathrm{D}$ used two different glass prisms. The alternative $\mathrm{C}$ used the frontal asymmetrical prism with base angle $\gamma$ of $13^{\circ}$ and apex angle $\beta$ of $90^{\circ}$ (Figure 1). The alternative D used the reverse symmetrical rectangular prism with base angle $\gamma$ of $90^{\circ}$ (Figure 2). The detailed design characteristics of considered glass prisms are described by Sourek et al. [25]. The glazing configurations are shown in Figure 3 and in Figure 4, individual layers in the triple glazing are described in Table 1.

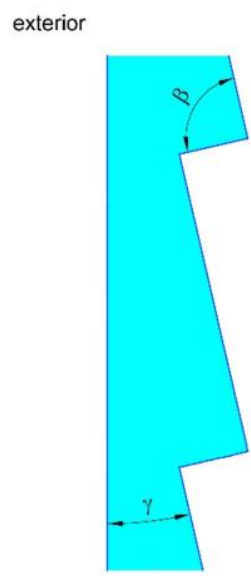

interior

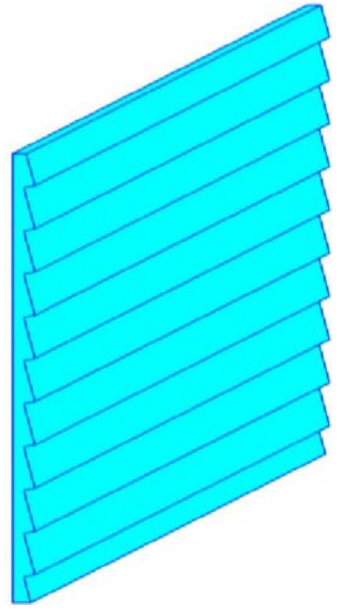

Fig. 1. Geometry of frontal asymmetrical prism.
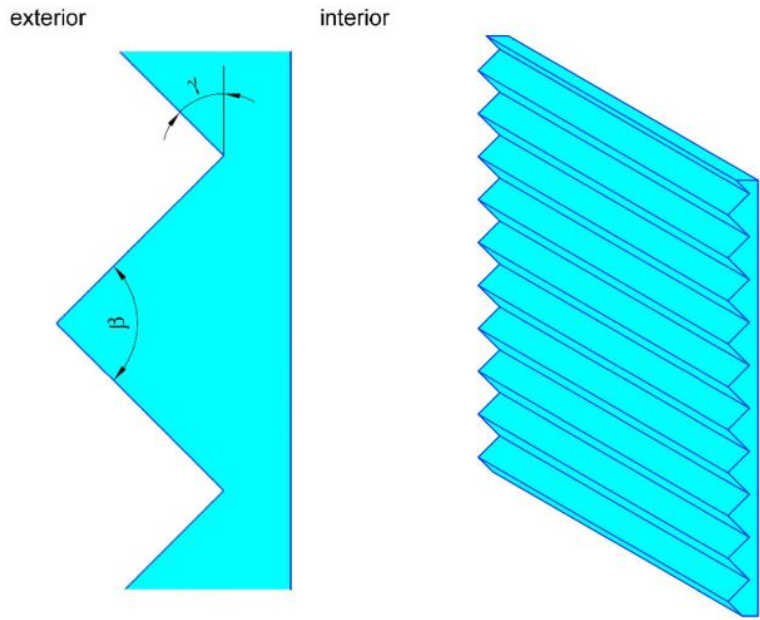

Fig. 2. Geometry of frontal reverse symmetrical prism.

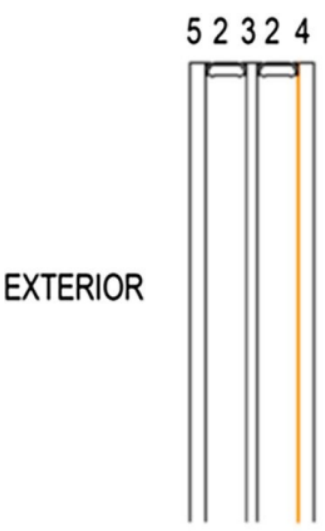

A
12324

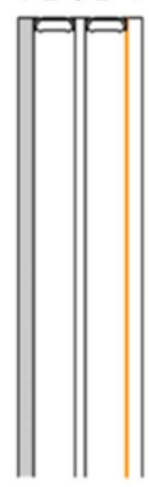

B
Fig. 3. Schematic layout of the considered glazing configurations (A and B). 


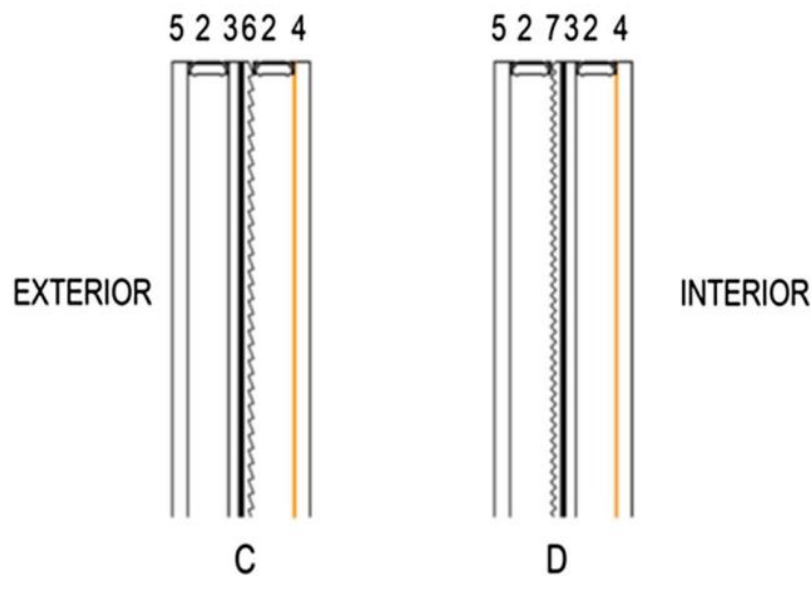

Fig. 4. Schematic layout of the considered glazing configurations (C and D).

Table 1. Layers description.

\begin{tabular}{|c|c|c|}
\hline Position & Thickness & Type of glass pane \\
\hline 1 & $6 \mathrm{~mm}$ & Solar protection pane \\
\hline 2 & $16 \mathrm{~mm}$ & $\begin{array}{c}\text { Thermally insulating frame, air } \\
\text { gap }\end{array}$ \\
\hline 3 & $3 \mathrm{~mm}$ & $\begin{array}{c}\text { Clear glass pane } \\
\text { Clear glass pane with low } \\
\text { emissivity coating }\end{array}$ \\
\hline 4 & $6 \mathrm{~mm}$ & \begin{tabular}{c} 
Clear glass pane \\
\hline 5
\end{tabular} \\
\hline 6 & $4 \mathrm{~mm}$ & Frontal asymmetrical glass prism \\
\hline
\end{tabular}

\section{Experimental characterization}

Experimental characterization of solar radiation transmittance for the considered alternatives has been carried out with the use of specific test stand. The test stand consists of source of collimated artificial solar radiation based on halogen lamp, circular light homogenizator, system of screens, the sample carrier with adjustable incidence angle, and movable radiation detector. The presented test stand allows to characterize the bi-directional solar radiation transmittance of flat samples with inhomogeneous structure (e. g. prismatic structures) at different incidence angles of solar radiation in two axes (Figure 5).

In order to characterize the transmittance of considered triple glazing alternatives, the comparative measurement method has been used. Generally, solar transmittance has been evaluated as ratio between irradiance transmitted by the sample and irradiance without sample for every measurement step (after every change of the sample position). The absolute values of irradiance were not necessary to be evaluated, transmittance has resulted directly from the ratio of detector electric signals. The results of the measurement for conventional glazing alternatives (samples A and B) are shown in Figure 6 and in Figure 7. The results of the measurement for the proposed glazing alternatives (samples C and D) are presented in Figure 8 and in Figure 9.

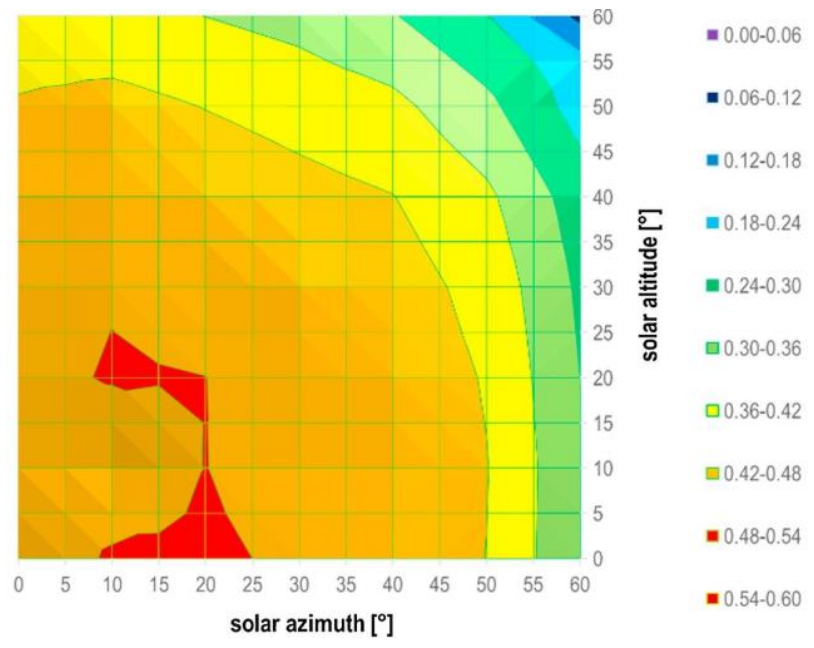

Fig. 6. Solar transmittance - experimental results for the sample A.

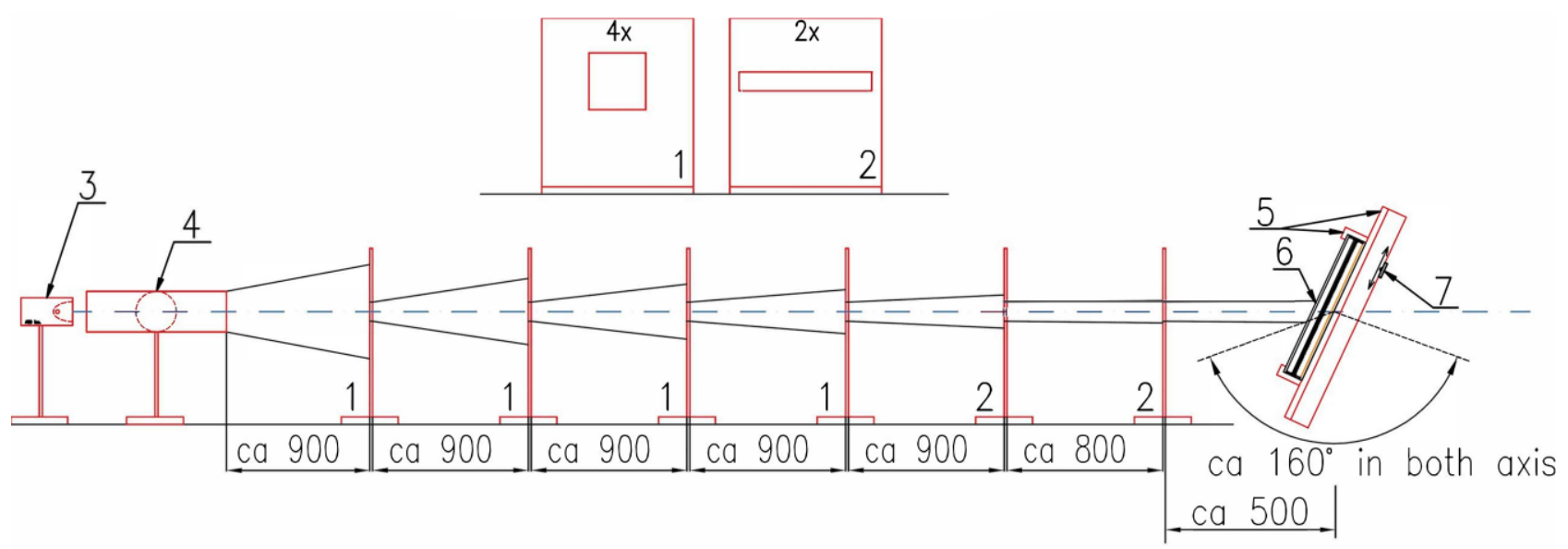

1,2 - Screens; 3 - Halogen lamp; 4 - Circular light homogenizator; 5 - Altazimuthal two-axis carrier; 6 - Sample; 7 - Detector

Fig. 5. Scheme of prismatic structure characterization test stand. 


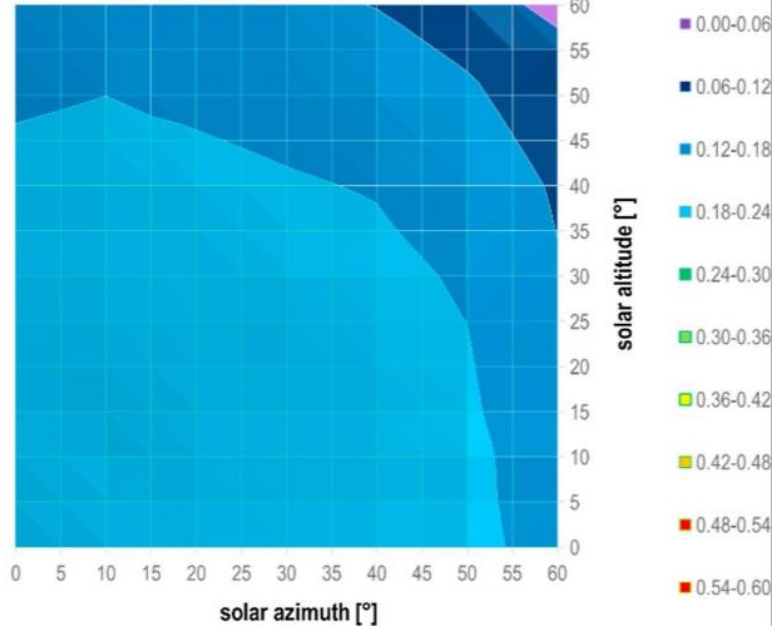

Fig. 7. Solar transmittance - experimental results for the sample B.
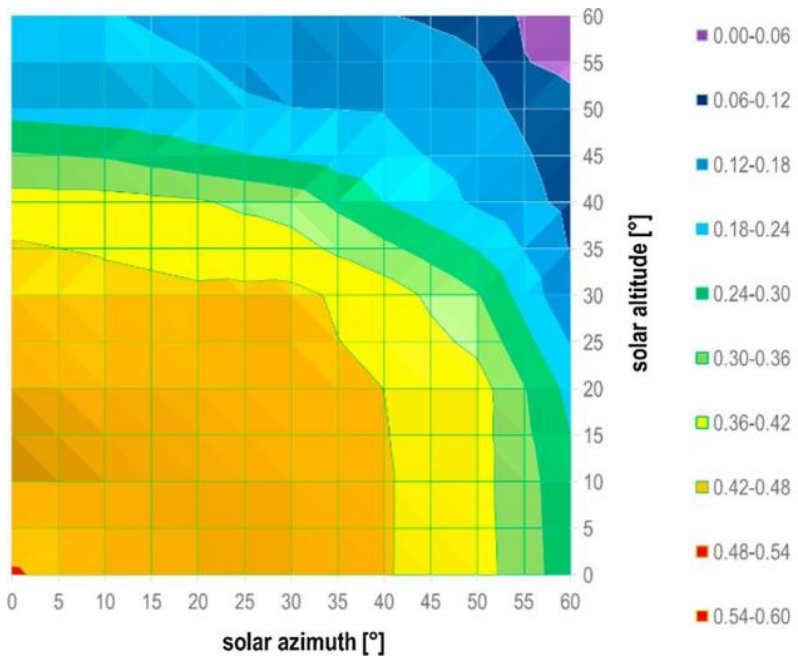

Fig. 8. Solar transmittance - experimental results for the sample $\mathrm{C}$.

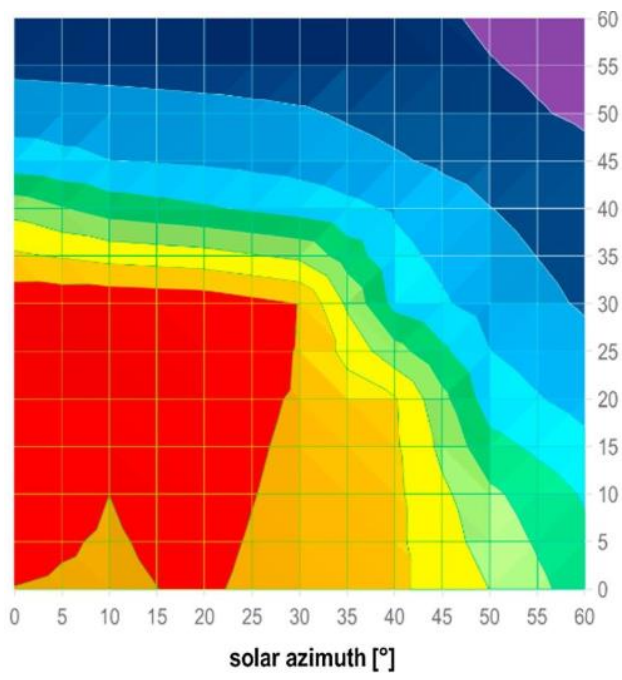

Fig. 9. Solar transmittance - experimental results for the sample D.

Firstly, the results of the measurement of the sample A indicate that solar transmittance reaches high values up to the angles $50^{\circ}$. Then the solar transmittance starts to decline due to increased reflection losses of flat interfaces glass-air of the individual layers. Similar behaviour but with significantly lower levels of transmittance results for solar protection triple glazing (sample B).

Secondly, it can be observed that transmittance characteristics of proposed alternatives C and D are significantly different. Moreover, there is a region with high transmittance for small solar altitude angles and a very narrow transition area to low transmittance region for solar altitude above $40^{\circ}$, especially for the sample D (with reverse symmetrical prism).

\section{Mathematical simulation of the office room}

To demonstrate the influence of the proposed glazing alternatives (C and D) on the typical office room energy balance, the simulation analysis has been performed for Prague climate conditions. The transmittance characteristics from experimental testing have been used as input information for an annual simulation of a typical office. Moreover, different facade orientations have been considered. The analysis has been provided by using TRNSYS and TNRBuild simulation software over the period of one year using the time step of 2 minutes. The dimensional sketch of the considered office room is shown in Figure 10.

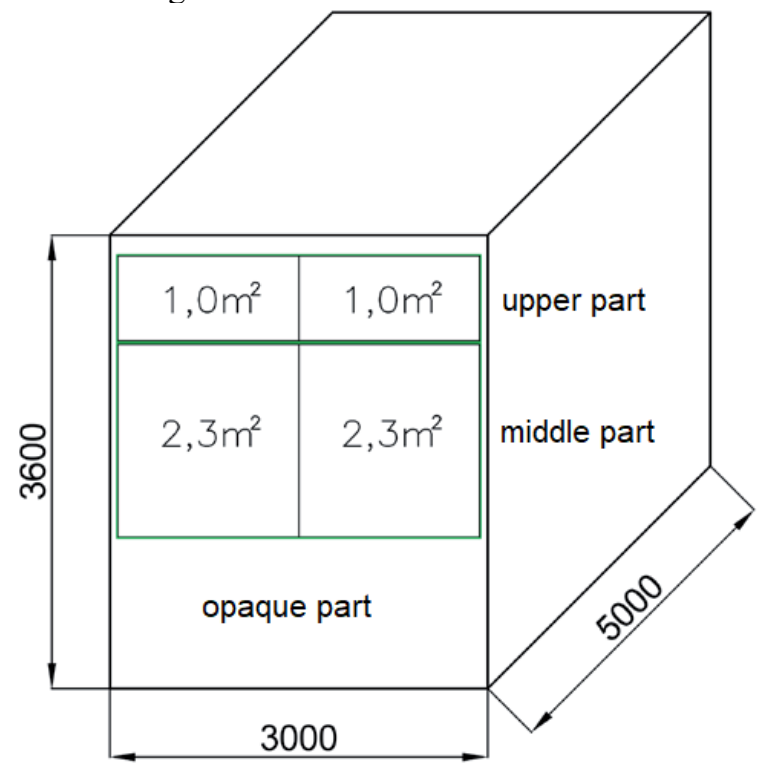

Fig. 10. Dimensional sketch of the considered office model.

The boundary conditions were given by "adjoining" premises to the office room, i.e. floor, ceiling, right and left wall have the same conditions behind the construction as the office itself (without heat transfer), the rear wall "adjoins" with the corridor space where the air temperature is assumed to be $20^{\circ} \mathrm{C}$. Façade has been analysed as a modular walling structure, which consists of upper and middle transparent parts and opaque bottom part with heat transfer coefficient $U$ of $0.133 \mathrm{~W} / \mathrm{m}^{2} \mathrm{~K}$.

Totally six façade alternatives have been simulated in TRNSYS software, including four alternatives with 
prismatic glass structure and two reference alternatives with conventional triple glazing. The reference alternatives $\mathrm{A} 1$ and $\mathrm{A} 2$ are based on a conventional glazing $\mathrm{A}$ and $\mathrm{B}$, which were used both for the upper and for the middle part. The alternatives A3 and A4 are based on the frontal asymmetrical prism (C) and the reverse symmetrical rectangular prism (D), which were used for the upper part, and the conventional clear glazing $\mathrm{A}$, which is used for the middle part. The alternatives A5 and $\mathrm{A} 6$ have the same configuration as $\mathrm{A} 3$ and $\mathrm{A} 4$, with the exception that the convection solar protection glazing B was used instead of the conventional clear glazing A. The opaque part has been considered the same for all analysed alternatives. The composition of four compared façade alternatives together with their reference alternatives are shown in Table 2.

Table 2. The considered façade alternatives.

\begin{tabular}{|c|c|c|c|}
\hline Alternative & Upper part & Middle part & Reference \\
\hline A1 & A & A & \\
\hline A2 & B & B & \\
\hline A3 & C & A & A1 \\
\hline A4 & D & A & A1 \\
\hline A5 & C & B & A2 \\
\hline A6 & D & B & A2 \\
\hline
\end{tabular}

The internal gains were determined based on the time profile of occupancy. It is assumed, that four people $(4 \times 60 \mathrm{~W}=240 \mathrm{~W})$ with laptops $(4 \times 58 \mathrm{~W}=232 \mathrm{~W})$ occupied the office room. The schedule of internal heat gains for a typical working day is shown in Figure 11.

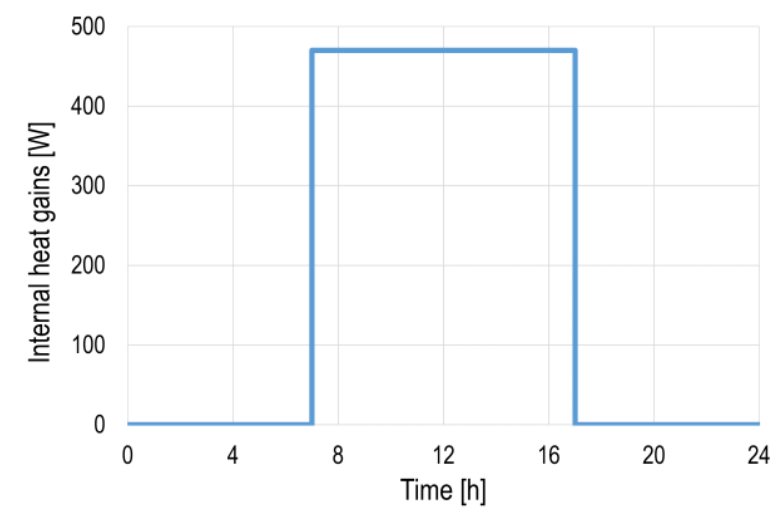

Fig. 11. Schedule of internal heat gains for the considered office model.

\section{Results and discussion}

The simulations have been provided for façade orientation angle from $0^{\circ}$ (south) to $90^{\circ}$ (west) with $10^{\circ}$ step. The results of the simulation are presented in Figure 12 and in Figure 13. It is important to note, that alternatives A3 and A4 have been compared with alternative $\mathrm{A} 1$ and alternatives $\mathrm{A} 5$ and $\mathrm{A} 6$ have been compared with alternative A2.

Firstly, the simulation results indicate, that the cooling energy demand of alternatives with clear triple glazing applied in the middle part and prismatic structures

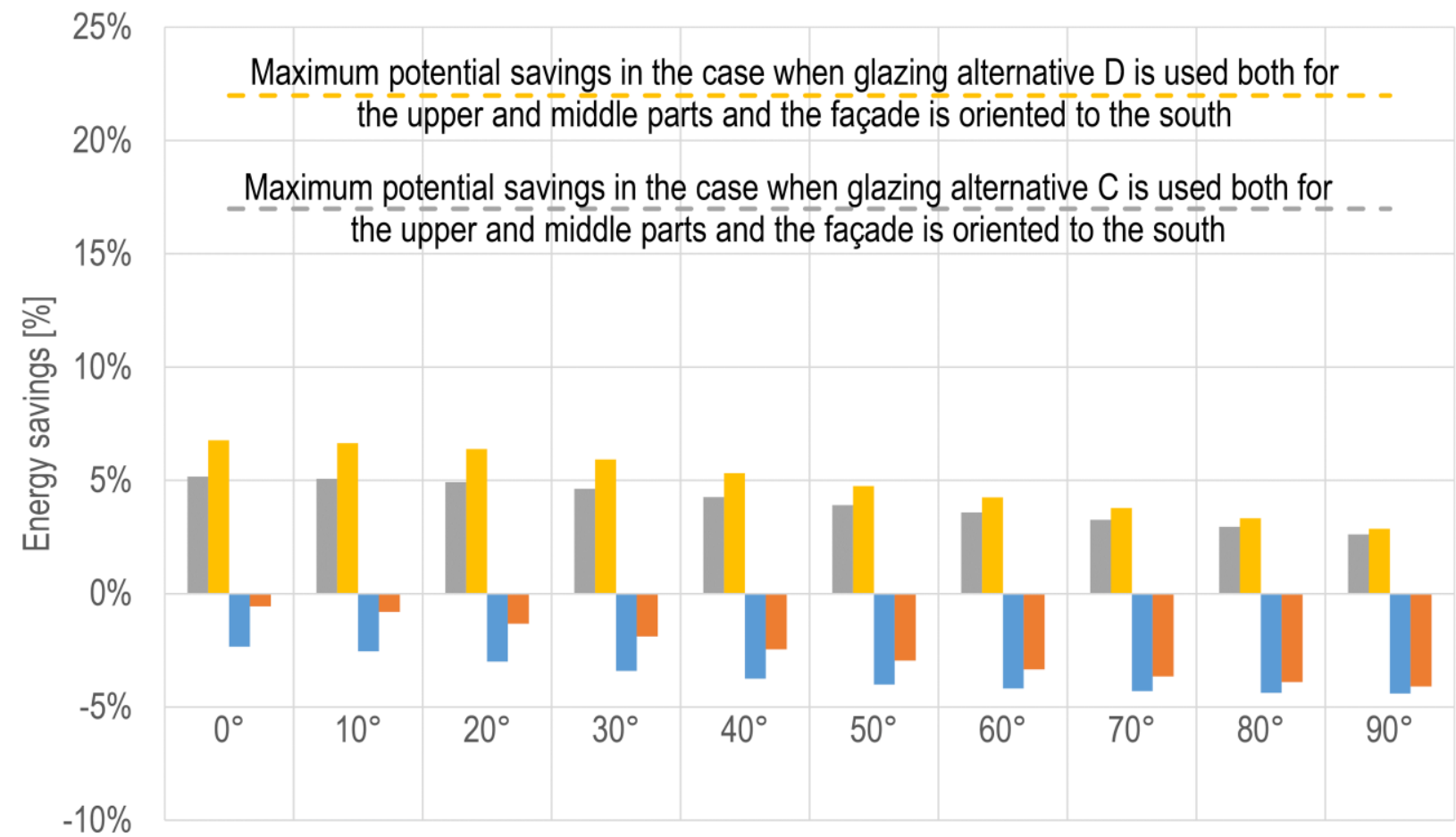

Façade azimuth $\left[{ }^{\circ}\right] 0^{\circ}=$ south; $90^{\circ}=$ west

$\square \mathrm{A} 3 \square \mathrm{A} 4 \square \mathrm{A} 5 \square \mathrm{A} 6$

Fig. 12. Cooling energy demand savings for the compared alternatives and for different azimuth of the façade. 


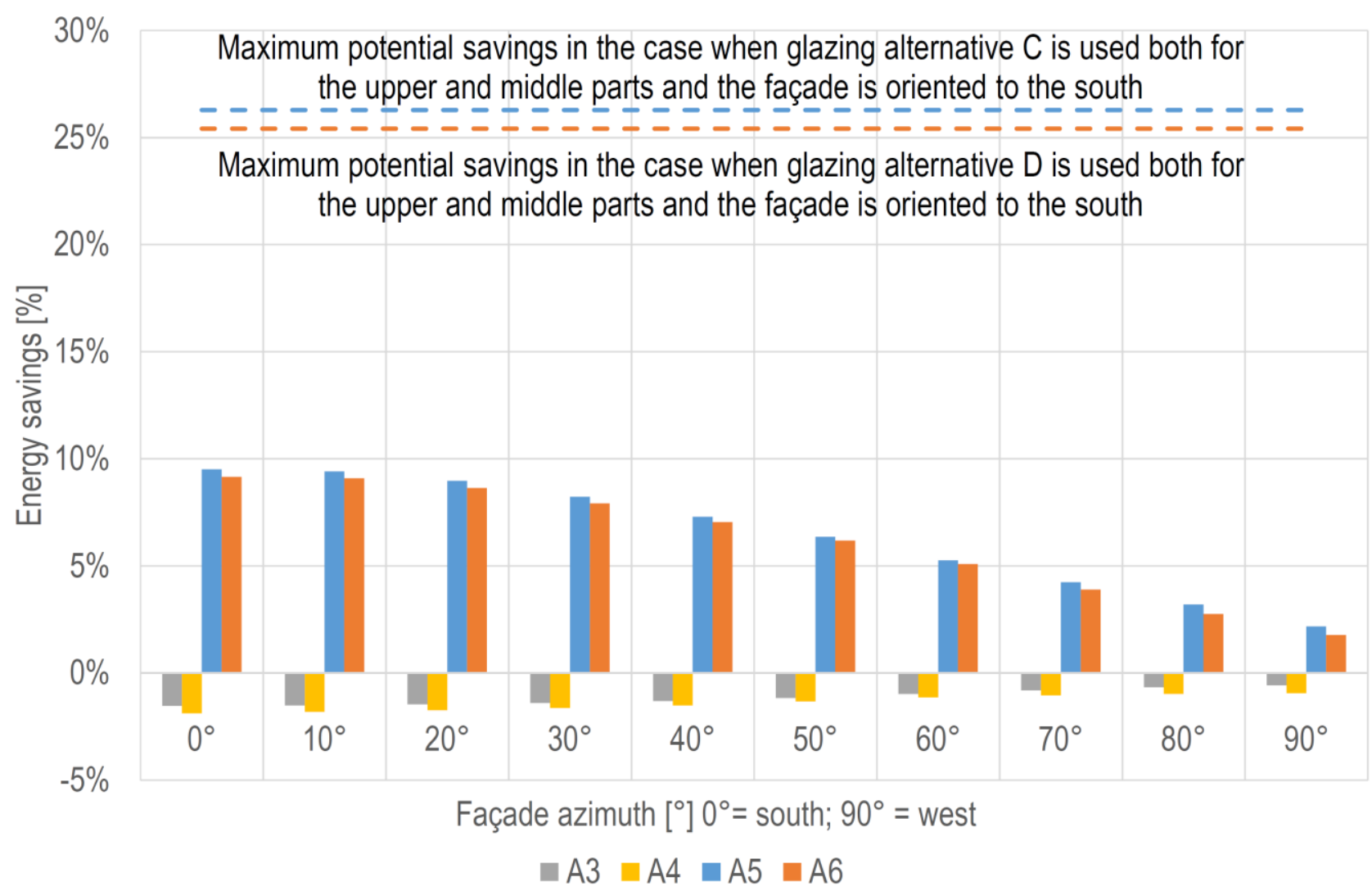

Fig. 13. Heating energy demand savings for the compared alternatives and for different azimuth of the façade.

applied in the upper part (A3 and A4) is lower compared to the A1 alternative where clear triple glazing (A) was used both for the upper and the middle part. It can be described by the fact, that the average solar transmittance of prismatic structures $(\mathrm{C}$ and $\mathrm{D})$ for the cooling period is lower compared to clear triple glazing (A). On the other hand, this effect has a negative influence on the heating energy demand, where due to low average solar transmittance during the heating period, the total heating energy demand is higher.

Secondly, the cooling energy demand of alternatives with solar protection triple glazing applied in the middle part and prismatic structures applied in the upper part (A5 and A6) is higher compared to the A2 alternative where solar protection triple glazing (B) was used both for the upper and the middle part. The reason for this is, that the average solar transmittance of prismatic structures $(\mathrm{C}$ and D) for the cooling period is higher compared to clear triple glazing (B). Moreover, the glazing alternative B (with solar protection) reflects solar radiation even for low solar altitude angles, while the prismatic glass structure (glazing alternatives $\mathrm{C}$ and D) at these low angles already transmit the direct solar radiation. On the other side, this effect has a positive influence on the heating energy demand, where due to high average solar transmittance during the heating period, the total heating energy demand is lower.

Finally, Figure 12 and Figure 13 indicate the maximum savings potential for the south oriented façade and assuming, that both transparent façade parts (upper and middle) would be made from prismatic glass structures. For the cooling energy demand, the maximum energy savings potential for the south oriented façade lies between $17 \%$ and $22 \%$. In the case of heating energy demand, the maximum energy savings potential for the south oriented façade varies between $26 \%$ and $27.5 \%$.

\section{Conclusion}

Detailed simulation analysis of the four different façade alternatives with prismatic glass structure has been provided. To obtain realistic bi-directional characteristics of solar radiation transmittance for detailed simulation, the experimental characterization of the transmittance has been performed for the triple glazing samples with and without the prisms. Triple glazing with the reverse symmetrical rectangular prism (apex angle $90^{\circ}$ ) has shown considerably better ability to block summer direct radiation, while allowing the winter solar heat gains. Based on the detailed office simulation results, it can be concluded, that there is a high potential for application of prismatic glazing in façades parts of office buildings due to possible reduction of energy demand for space heating and space cooling.

This work has been supported by the Ministry of Education, Youth and Sports within National Sustainability Programme I, project No. LO1605.

\section{References}

1. R. P. Leslie, Build. Environ. 38, 381 (2003)

2. K. Konis, Build. Environ. 59, 662 (2013) 
3. E. Rodriguez-Ubinas, C. Montero, M. Porteros, S Vega, I Navarro, M Castillo-Cagigal, E. Matallanas, A. Gutiérrez, Energy Build. 83, 10 (2014)

4. C. E. Ochoa, M. B. C. Aries, E. J. van Loenen, J. L. M. Hensen, Appl. Energy 95, 238 (2012)

5. M. R. Fontenelle, L. E. G. Bastos, Build. Environ. 74, 96 (2014)

6. L. G. Valladares-Rendón, G. Schmid, S-L. Lo, Energy Build. 140, 458 (2017)

7. T. E. Kuhn, C. Bühler, W. J. Platzer, Sol. Energy 69, $59(2001)$

8. E. J. Gago, T. Muneer, M. Knez, H. Köster, Renew. Sustain. Energy Rev. 41, 1 (2015)

9. H. Shen, A. Tzempelikos, Build. Environ. 59, 303 (2013)

10. A. Mahdavi, S. Dervishi, Proc. of Building Simulation (2011)

11. M. Liu, K. B. Wittchen, P. K. Heiselberg, Appl. Energy 145, 43 (2015)

12. I. Senzo, Light transmitting panel (US Patent 3,393,034, 1968)

13. H. Köster, Scheibenverbund als Dach-oder Fassadenelement mit reflektierenden Profilen zur Lichtsteuerung (German patent application DE A1 E04D003-35, 1984)

14. Y. Bar-Yonah, Selectively light transmitting panel (US Patent 4,519,675, 1985)

15. D. L. Critten, Sol. Energy 41, 583 (1988)

16. K. Kurata, Sol. Energy 46, 53 (1991)

17. D. Christoffers, Sol. Energy 57, 339 (1996)

18. W. Lorenz, Sol. Energy 63, 79 (1998)

19. W. Lorenz, Sol. Energy 70, 109 (2001)

20. J. Korecko, V. Jirka, B. Sourek, J. Cerveny, Sol. Energy 84, 1794 (2010)

21. M. Sabry, Energy 107, 473 (2016)

22. G. Walze, P. Nitz, J. Ell, A. Georg, A. Gombert, W. Hossfeld, Sol. energy Mater. Sol. cells 89, 233 (2005)

23. G. W. Mbise, D. Le Bellac, G. A. Niklasson, C. G. Granqvist, J. Phys. D. Appl. Phys. 30, 2103 (1997)

24. R. S. Zakirullin, S. N. Letuta, Sol. Energy 120, 585 (2015)

25. B. Sourek, V. Jirka, V. Shemelin, T. Matuska, Sol. Energy 158, 440 (2017) 